\title{
Does It Look Painful or Disgusting? Ask Your Parietal and Cingulate Cortex
}

\author{
Francesca Benuzzi, ${ }^{1}$ Fausta Lui, ${ }^{2}$ Davide Duzzi, ${ }^{2}$ Paolo F. Nichelli, ${ }^{1}$ and Carlo A. Porro ${ }^{2}$ \\ Dipartimenti di ${ }^{1}$ Neuroscienze and ${ }^{2}$ Scienze Biomediche, Università di Modena e Reggio Emilia, 41100 Modena, Italy
}

\begin{abstract}
Looking at still images of body parts in situations that are likely to cause pain has been shown to be associated with activation in some brain areas involved in pain processing. Because pain involves both sensory components and negative affect, it is of interest to explore whether the visually evoked representations of pain and of other negative emotions overlap. By means of event-related functional magnetic resonance imaging, here we compare the brain areas recruited, in female volunteers, by the observation of painful, disgusting, or neutral stimuli delivered to one hand or foot. Several cortical foci were activated by the observation of both painful and disgusting video clips, including portions of the medial prefrontal cortex, anterior, mid-, and posterior cingulate cortex, left posterior insula, and right parietal operculum. Signal changes in perigenual cingulate and left anterior insula were linearly related to the perceived unpleasantness, when the individual differences in susceptibility to aversive stimuli were taken into account. Painful scenes selectively induced activation of left parietal foci, including the parietal operculum, the postcentral gyrus, and adjacent portions of the posterior parietal cortex. In contrast, brain foci specific for disgusting scenes were found in the posterior cingulate cortex. These data show both similarities and differences between the brain patterns of activity related to the observation of noxious or disgusting stimuli. Namely, the parietal cortex appears to be particularly involved in the recognition of noxious environmental stimuli, suggesting that areas involved in sensory aspects of pain are specifically triggered by observing noxious events.
\end{abstract}

Key words: cerebral cortex; disgust; empathy; functional magnetic resonance imaging; observation; pain

\section{Introduction}

Our ability to recognize noxious environmental events and pain in other people is likely to play an important protective and social role, allowing for vicarious learning about dangers and for prosocial behavior toward conspecifics (Williams, 2002; Goubert et al., 2005). There is evidence for shared neuronal networks in the human brain, active when we both feel our own emotions and observe emotional reactions in others; these networks might underlie our ability to empathize (Adolphs, 2002; Decety and Jackson, 2004; Gallese et al., 2004). Recently, considerable interest has been devoted to the neural correlates of "empathy for pain," which have been investigated with different experimental paradigms (de Vignemont and Singer, 2006; Jackson et al., 2006a).

In a first approach, the brain responses associated with knowing that one's own partner was receiving a painful stimulation, as indicated by a symbolic visual cue, were explored by functional magnetic resonance imaging (fMRI) (Singer et al., 2004). A second approach has been to study the fMRI activity engaged by observing pain-related behavior of unknown subjects [facial expressions of pain (Botvinick et al., 2005; Simon et al., 2006; Lamm

Received Sept. 3, 2007; revised Nov. 21, 2007; accepted Nov. 21, 2007.

This work was supported by grants from Ministero dell'Università e della Ricerca (C.A.P.). We thank Dr. Marco Serafini (Azienda Sanitaria Locale Modena), Dr. Luca Nocetti (Azienda Policlinico Modena), and Dr. Matteo Corradini (Dipartimento di Scienze Biomediche, Università Modena e Reggio Emilia) for their excellent technical help and the Fondazione Cassa di Risparmio di Modena for its financial support to the Modena Magnetic Resonance Center.

Correspondence should be addressed to Prof. Carlo Adolfo Porro, Dipartimento di Scienze Biomediche, Sezione Fisiologia, Università di Modena e Reggio Emilia, Via Campi 287, I-41100 Modena, Italy. E-mail: porro@unimore.it. D01:10.1523/JNEUROSCI.4012-07.2008

Copyright $\odot 2008$ Society for Neuroscience $\quad$ 0270-6474/08/280923-09\$15.00/0 et al., 2007; Saarela et al., 2007)]. In a third approach, viewing pictures of body parts of unknown actors in painful situations was compared with viewing nonpainful stimuli, using fMRI (Morrison et al., 2004; Jackson et al., 2005, 2006b; Gu and Han, 2007; Morrison and Downing, 2007), transcranial magnetic stimulation (Avenanti et al., 2005, 2006), or electroencephalography (Bufalari et al., 2007).

Despite the different kinds of information conveyed by visual stimuli in the above mentioned paradigms, anterior insular and anterior mid-cingulate cortex (aMCC) responses were commonly found when comparing painful with neutral conditions. The involvement of parietal areas, such as the primary somatosensory cortex (SI) (Bufalari et al., 2007), parietal operculum (PO), and/or posterior parietal cortex (Botvinick et al., 2005; Jackson et al., 2006b; Singer et al., 2006; Ogino et al., 2007; Moriguchi et al., 2007; Saarela et al., 2007), has also been demonstrated, although less consistently.

An important and essentially unresolved issue concerns the specificity of brain activity associated with observing and representing painful conditions compared with other negative emotional states or unpleasant stimuli (Godinho et al., 2006; Simon et al., 2006; Ogino et al., 2007). Indeed, although pain- and emotion-related processes clearly overlap to some extent (Rainville, 2002), the conscious experience of acute pain always involves a specific sensory dimension. Moreover, pain expression has been described to be unique and distinct from those of basic emotions (Williams, 2002; Simon et al., 2008).

In the present study, we aimed at investigating the similarities 
and differences between the brain circuits involved in recognizing different kinds of unpleasant and aversive cutaneous stimuli (painful vs disgusting), using an eventrelated fMRI design. We hypothesized that the activity of parietal cortices, which are likely to play a crucial role in the sensory dimension of pain (Porro, 2003; Price et al., 2003), would differ when observing painful or nonpainful unpleasant events.

\section{Materials and Methods}

Volunteers. Fifteen right-handed healthy women (age, 19-31 years; mean, 23.5 years), with no history of neurological or psychiatric illness, took part in the fMRI study. We chose to perform experiments only in female volunteers as in a previous study on pain empathy (Singer et al., 2004), in light of potential gender differences in empathy processes and modulation (Decety and Jackson, 2004; Singer et al., 2006). Handedness was assessed by means of the Edinburgh Inventory (Oldfield, 1971). All subjects

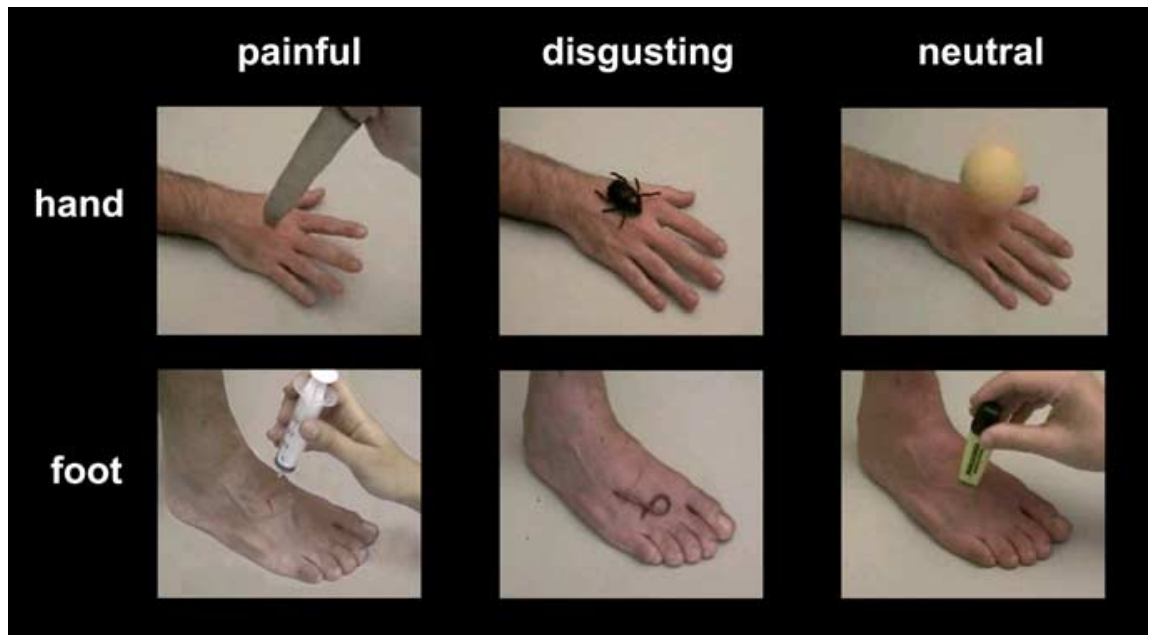

Figure 1. Sample frames extracted from some video clips representing painful (left), disgusting (middle), and neutral (right) stimuli. All video clips began with $200-400 \mathrm{~ms}$ of a static hand or foot picture, followed by a stimulus rapidly approaching and contacting the skin. Needles and knifes apparently punctured the hand or foot, but actually they did not: the images were digitally corrected to simulate bleeding. gave their written informed consent to take part in the study, which had been approved previously by the local Ethics Committee.

Stimuli validation. One hundred five video clips were presented to a group of 14 women (age, 21-57 years; mean age, 35.1 years), different from the ones who subsequently took part in the fMRI study. We chose to present video clips to offer a more realistic representation than that provided by still pictures. Each video clip lasted $1 \mathrm{~s}$ and represented the right hand or the right foot of an unknown male actor, in one of three different conditions: neutral $(\mathrm{N})$, painful $(\mathrm{P})$, and disgusting $(\mathrm{D})$. In the neutral condition, the hand/foot was touched by a neutral stimulus (e.g., a ball or a pen); in the disgusting condition, it was touched by a disgusting stimulus (spider, beetle, earthworm, or grasshopper); in the painful condition the hand/foot was wounded by a knife or a syringe. Although the term "disgust" is etymologically related to aversive stimuli in the olfaction and taste domains, by extension it has become associated with other classes of stimuli causing strong dislike and repulsion, such as some animal species, deformed body parts, poor hygiene, and body products (Calder et al., 2000; Schienle et al., 2002). In the present study, we chose to present animals touching body parts to make the disgusting stimuli as similar as possible to the other two classes with respect to skin contact. Both painful and disgusting video clips represented a biological agent acting on the skin: a human hand holding a sharp or rounded tool/object for painful or neutral stimuli, respectively; an animal falling on the skin for disgusting stimuli. After each stimulus presentation, the volunteers were asked to rate how disgusting and painful was the video clip on two separate $0-10$ point scales. The video clips rated as the most painful or the most disgusting were selected for the fMRI study.

Experimental design. The final set of video clips presented during the fMRI experiments comprised 20 neutral stimuli (10 representing the right hand and 10 representing the right foot; mean D rating obtained in the validation study, 0.03; mean P rating, 0.09), 20 disgusting stimuli (10 representing the right hand and 10 representing the right foot; mean D rating, 4.31; mean $P$ rating, 1.36), and 20 painful stimuli (10 representing the right hand and 10 representing the right foot; mean D rating, 3.99; mean $P$ rating, 7.85). Examples of frames taken from the video clips are presented in Figure 1. In each video clip, the hand or foot appeared in an allocentric viewpoint. Each video clip was presented only once and covered a visual angle of $12-13^{\circ}$, depending on the subject's head position.

An event-related paradigm was used. Five runs, 12 trials each, were performed, for a total of 60 trials for each subject. In each trial, the volunteers were asked to watch a video clip carefully and, after a $10 \mathrm{~s}$ interval, to rate the perceived unpleasantness of the stimulus. To this end, they had to use their right-hand to rotate a knob; this moved a red cursor on a visual analog scale (VAS) that was projected on the screen for $5 \mathrm{~s}$,

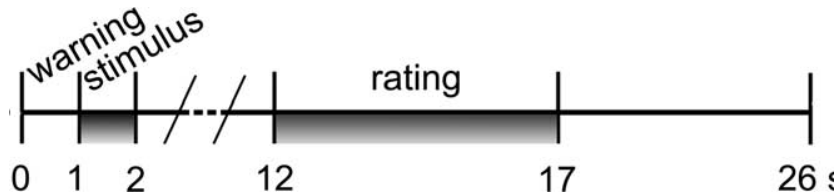

Figure 2. Experimental design. Temporal sequence of events during each trial. For details, see Materials and Methods.

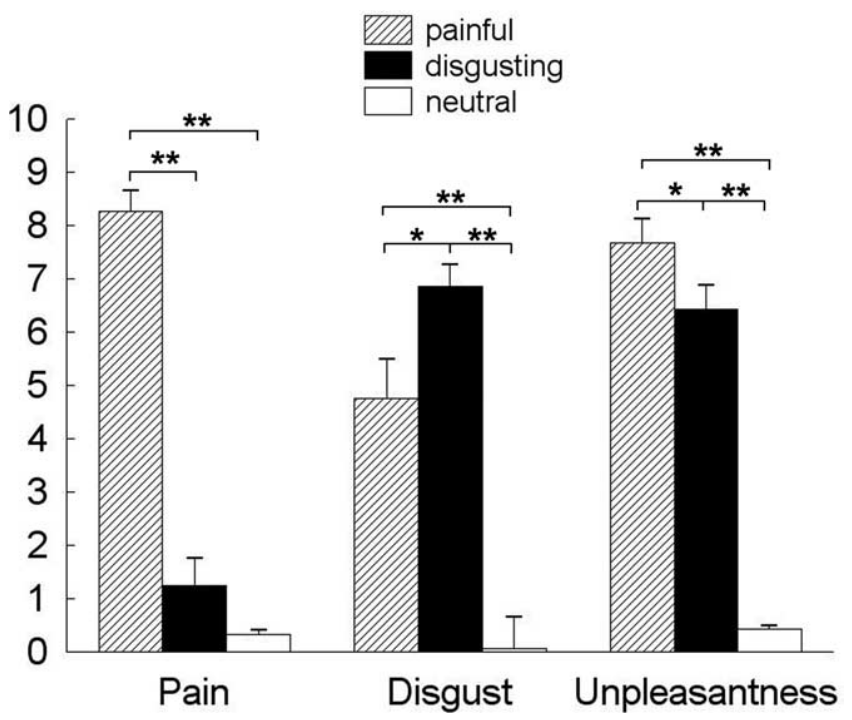

Figure 3. On-line (unpleasantness) and off-line (disgust and painfulness) ratings of visually presented stimuli. ${ }^{*} p<0.05$; ${ }^{* *} p<0.0001$.

anchored at "not unpleasant at all" and "the highest imaginable unpleasantness." Volunteers were accustomed to the rating procedures before the actual fMRI experiments.

Each trial lasted $26 \mathrm{~s}$ and began with a brief change of the background color (from black to blue) as a visual warning cue. Then the following events ensued: black screen ( $\sim 500 \mathrm{~ms})$, stimulus presentation ( $1 \mathrm{~s})$, black screen (10 s), VAS presentation (5 s), black screen (9 s) (Fig. 2). The warning cue was introduced to prompt subjects about the occurrence of the next video clip but did not provide any hint about the kind of the represented stimulus (N, D, or P) or body site (hand or foot). Behavioral 

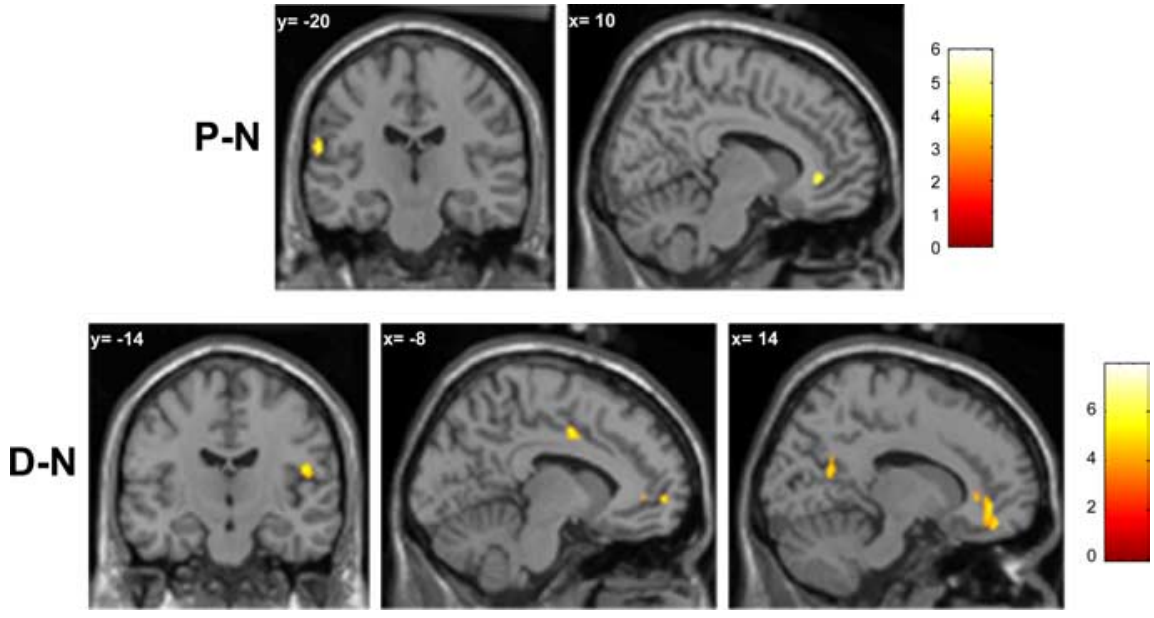

Figure 4. Top, Cortical foci active during the observation of painful video clips, identified from the $(P-N)$ contrast. Bottom, Cortical foci active during the observation of disgusting video clips, identified from the $(D-N)$ contrast. Maps are thresholded at $p<0.001$ uncorrected for multiple comparisons, with a cluster extent threshold $(k)$ of 25 voxels in the interpolated images (200 $\left.\mathrm{mm}^{3}, \mathrm{p}<0.05\right)$.

responses were collected during the scanning sessions by means of a custom-made software developed in Visual Basic 6 (http://digilander. libero.it/marco_serafini/stimoli_video/). The same software was used to present stimuli via the IFIS (Invivo, Orlando, FL) remote display. VAS ratings were transformed in a numerical scale $(0-100)$.

At the end of the scanning session, the volunteers were presented again with the same video clips and asked to rate how disgusting and painful they had perceived each video clip during the scanning session on two separate 0-10 point scales. Moreover, they were asked to complete an Italian version of a Fear Survey Schedule (IP-R) (Sanavio et al., 1986). The IP-R provides quantitative information about subjects' reactions to a great variety of fearful stimuli on five categories: "natural disasters, injury, illness, and death," "social phobia," "harmless animals," "agoraphobia and claustrophobia," and "blood and medical procedures."

fMRI data acquisition and analyses. Data were acquired with a Philips Intera system at $3 \mathrm{~T}$ and a gradient-echo echo-planar sequence [repetition time (TR), $2000 \mathrm{~ms}$; echo time (TE), $30 \mathrm{~ms}$; field of view, $240 \mathrm{~mm}$; $128 \times 128$ matrix; 24 oblique slices approximately parallel to the Sylvian fissure, $3 \mathrm{~mm}$ each with a $0.5 \mathrm{~mm}$ gap]. A high-resolution T1-weighted anatomical image was acquired for each subject to allow anatomical localization (TR, $9.9 \mathrm{~ms}$; TE, $4.6 \mathrm{~ms}$; 170 sagittal slices; voxel size, $1 \times 1 \times$ $1 \mathrm{~mm}$ ). The Matlab 6.5 and SPM2 (Wellcome Department of Imaging Neuroscience, London, UK) softwares were used for data analysis. For each subject, all functional volumes were realigned to the first volume acquired, slice time corrected, normalized to the MNI (Montreal Neurological Institute) template implemented in SPM2, and smoothed with a $6 \times 6 \times 9 \mathrm{~mm}$ full-width at half-maximum Gaussian kernel.

Data analysis was performed by means of the SPM2 general linear model. The different stimuli (P, D, or N, hand or foot video clips) and the rating period were entered as regressors. We report here only the results concerning the observation of video clips. We used a $2 \times 3$ factorial design. The first factor was the body part (hand or foot), and the second factor was the condition (neutral, disgusting, or painful). For each volunteer, video clips were assigned to the different conditions based on her individual behavioral responses. First, the on-line VAS ratings were used to discriminate between neutral and unpleasant stimuli. The cutoff was set at 15 on the unpleasantness scale $(0-100)$. The distinction between painful and disgusting stimuli was made on the basis of the volunteer's postscan behavioral responses; stimuli were considered to be painful if they were assigned a higher score for painfulness than for disgust and vice versa.

Condition effects were estimated according to the general linear model, and condition-specific effects were compared using several linear contrasts. The individual contrast images were then submitted to a second-level random-effect analysis with separate one-sample $t$ test. A double statistical threshold (intensity and spatial extent) was adopted: only clusters with a voxelwise intensity threshold of $p<0.001$ (uncorrected) and a spatial extent threshold of $p<$ 0.05 (uncorrected) were considered to be significant. To investigate the spatial overlap of regions displaying selective fMRI signal increases during the observation of both painful and disgusting video clips, we performed a conjunction analysis of the two contrasts, painful versus neutral and disgusting versus neutral $[(\mathrm{P}-\mathrm{N})+(\mathrm{D}-\mathrm{N})]$.

An additional analysis was performed to map regions whose activity was related to the perceived unpleasantness. To this end, a parametric analysis was first conducted in each subject to reveal the cortical regions whose activity showed a linear relationship with the unpleasantness ratings. Subsequently, to take into account the individual differences in susceptibility to the experimental stimuli, both the contrast images obtained from this parametric analysis and the IP-R general score for each single subject were entered in a second-level simple regression analysis.

For all analyses, coordinates in Talairach space (Talairach and Tournoux, 1988) were obtained by applying the Matthew Brett correction (mni2tal: http://www.mrc-cbu.cam.ac.uk/Imaging/mnispace.html) to the SPM MNI coordinates.

Behavioral data analyses. Subjective postscan ratings were compared by an ANOVA with three factors: condition (pain, disgust, and neutral), limb (hand and foot), and rating (painful and disgusting). To compare the perceived unpleasantness during the fMRI experiments, a separate ANOVA was performed with two factors: condition (pain, disgust, and neutral) and limb (hand and foot). Post hoc analyses were done using the Scheffé's test for multiple comparisons.

\section{Results}

\section{Subjective ratings}

Mean \pm SEM scores of perceived unpleasantness, painfulness, and disgust for the different classes of visual stimuli, in the 15 volunteers taking part to the fMRI study, are reported in Figure 3. ANOVA on postscan scores showed a significant effect of the factors condition $\left(F_{(2,28)}=95.75 ; p<0.0001\right)$, rating $\left(F_{(1,14)}=\right.$ 9.92; $p<0.0001)$, and their interaction $\left(F_{(2,28)}=85.4 ; p<\right.$ $0.0001)$. Post hoc analyses showed that pain ratings were higher for $\mathrm{P}$ videos than for both $\mathrm{D}$ and $\mathrm{N}$ videos $(p<0.0001$ in both instances), whereas disgust ratings were higher for $\mathrm{D}$ videos than for both $\mathrm{P}(p<0.02)$ and $\mathrm{N}(p<0.0001)$ videos. No significant difference was found in subjective ratings for limb (hand or foot).

Perceived unpleasantness was significantly different between $\mathrm{P}, \mathrm{D}$, and $\mathrm{N}$ videos $\left(F_{(1,14)}=164.83 ; p<0.0001\right)$, but no differences were found according to limb. Post hoc analyses showed that scores of perceived unpleasantness were significantly higher for $\mathrm{P}$ and $\mathrm{D}$ than $\mathrm{N}$ videos ( $p<0.0001$ in both instances); also, they were significantly higher for $\mathrm{P}$ than for $\mathrm{D}$ videos $(p<0.05)$.

\section{fMRI data}

When contrasting observation of stimuli to the hand or foot, no cluster was detected meeting the adopted statistical threshold; therefore, video clips depicting the hand or foot were considered together for additional analyses. As expected, observation of each class of stimuli (N, P, or D) induced higher fMRI signals with respect to baseline in a large array of cortical areas: active foci were found in the bilateral occipito-temporal and frontal premotor cortex, as well as in posterior parietal areas, mainly of the left 
Table 1. fMRI signal increases and decreases during the observation of painful stimuli

\begin{tabular}{|c|c|c|c|c|c|c|c|c|c|c|}
\hline & \multicolumn{2}{|c|}{ Cluster level } & \multicolumn{2}{|c|}{ Voxel level } & \multicolumn{3}{|c|}{ MNI coordinates (mm) } & \multicolumn{3}{|c|}{ Talairach coordinates (mm) } \\
\hline & $k$ & $p$ & $Z$ & $p$ & $x$ & $y$ & $Z$ & $x$ & $y$ & $Z$ \\
\hline \multicolumn{11}{|c|}{ Brain areas displaying selective fMRI signal increases during the observation of painful stimuli $(P-N)$} \\
\hline \multirow[t]{2}{*}{$\mathrm{pACC}(\mathrm{BA} 24 / 32)$} & 48 & 0.006 & 4.16 & $<0.001$ & 0 & 28 & 2 & 0 & 27 & 0 \\
\hline & & & 3.94 & $<0.001$ & 10 & 36 & -2 & 10 & 35 & -3 \\
\hline \multirow[t]{2}{*}{ L postcentral gyrus } & 57 & 0.003 & 3.86 & $<0.001$ & -62 & -20 & 18 & -61 & -19 & 18 \\
\hline & & & 3.63 & $<0.001$ & -66 & -14 & 24 & -65 & -12 & 23 \\
\hline \multicolumn{11}{|c|}{ Brain areas displaying selective fMRI signal decreases during the observation of painful stimuli (N $-\mathrm{P})$} \\
\hline \multirow[t]{3}{*}{ R S/M frontal gyrus (BA 10, 11) } & 114 & 0.000 & 4.20 & $<0.001$ & 32 & 60 & -8 & 32 & 58 & -10 \\
\hline & & & 3.67 & $<0.001$ & 26 & 66 & 4 & 26 & 64 & 0 \\
\hline & & & 3.28 & 0.001 & 26 & 56 & -12 & 26 & 54 & -13 \\
\hline R middle frontal gyrus (BA 10, 11, 47) & 38 & 0.012 & 4.25 & $<0.001$ & 46 & 52 & -8 & 46 & 50 & -9 \\
\hline R middle frontal gyrus (BA 6) & 59 & 0.003 & 5.30 & $<0.001$ & 22 & 10 & 68 & 22 & 13 & 62 \\
\hline \multirow[t]{3}{*}{ R inferior parietal lobule (BA 40) } & 113 & 0.000 & 4.14 & $<0.001$ & 60 & -48 & 40 & 59 & -45 & 39 \\
\hline & & & 3.81 & $<0.001$ & 52 & -52 & 50 & 51 & -48 & 48 \\
\hline & & & 3.72 & $<0.001$ & 50 & -50 & 42 & 50 & -47 & 41 \\
\hline \multirow[t]{3}{*}{ R medial parietal cortex/superior parietal lobule (BA 7) } & 81 & 0.001 & 3.97 & $<0.001$ & 16 & -64 & 56 & 16 & -59 & 55 \\
\hline & & & 3.50 & $<0.001$ & 8 & -60 & 58 & 8 & -55 & 56 \\
\hline & & & 3.35 & $<0.001$ & 8 & -70 & 58 & 8 & -65 & 57 \\
\hline R angular gyrus (BA 39) & 28 & 0.027 & 3.52 & $<0.001$ & 38 & -80 & 28 & 38 & -76 & 30 \\
\hline R medial parietal cortex (BA 7) & 121 & 0.000 & 4.61 & $<0.001$ & 16 & -82 & 44 & 16 & -77 & 44 \\
\hline
\end{tabular}

R, Right; L, left; BA, Brodmann area.

Table 2. fMRI signal increases and decreases during the observation of disgusting stimuli

\begin{tabular}{|c|c|c|c|c|c|c|c|c|c|c|}
\hline & \multicolumn{2}{|c|}{ Cluster level } & \multicolumn{2}{|c|}{ Voxel level } & \multicolumn{3}{|c|}{ MNI coordinates (mm) } & \multicolumn{3}{|c|}{ Talairach coordinates (mm) } \\
\hline & $k$ & $p$ & $Z$ & $p$ & $x$ & $y$ & Z & $x$ & $y$ & $Z$ \\
\hline \multicolumn{11}{|c|}{ Cortical areas displaying selective $f M R I$ signal increases during the observation of disgusting stimuli $(D-N)$} \\
\hline \multirow[t]{2}{*}{ L medial prefrontal cortex (BA 10) } & 52 & 0.006 & 4.16 & $<0.001$ & -14 & 60 & 4 & -14 & 58 & 1 \\
\hline & & & 3.79 & $<0.001$ & -8 & 56 & 0 & -8 & 54 & -3 \\
\hline $\mathrm{RpACC}(\mathrm{BA24/32)}$ & 306 & $<0.001$ & 4.80 & $<0.001$ & 2 & 36 & -14 & 2 & 34 & -13 \\
\hline \multirow[t]{2}{*}{ Medial prefrontal cortex (BA 11) } & & & 4.05 & $<0.001$ & 10 & 38 & 2 & 10 & 37 & 0 \\
\hline & & & 3.67 & $<0.001$ & 14 & 46 & -16 & 14 & 44 & -16 \\
\hline L pACC (BA 32) & 35 & 0.02 & 3.52 & $<0.001$ & -4 & 46 & 4 & -4 & 45 & 1 \\
\hline \multirow[t]{2}{*}{ Mid-cingulate cortex (BA 24'/32') } & 40 & 0.013 & 3.91 & $<0.001$ & -8 & -2 & 42 & -8 & 0 & 39 \\
\hline & & & 3.18 & 0.001 & 0 & -2 & 36 & 0 & 0 & 33 \\
\hline R parietal operculum (BA 43) & 38 & 0.015 & 4.02 & $<0.001$ & 50 & -14 & 18 & 50 & -13 & 17 \\
\hline R posterior cingulate (BA 31) & 81 & 0.001 & 3.76 & $<0.001$ & 20 & -58 & 18 & 20 & -55 & 19 \\
\hline \multicolumn{11}{|c|}{ Brain areas displaying selective fMRI signal decreases during the observation of disgusting stimuli (N $-\mathrm{D})$} \\
\hline \multirow[t]{2}{*}{ R superior frontal gyrus (BA 8) } & 61 & 0.003 & 4.28 & $<0.001$ & 20 & 20 & 48 & 20 & 22 & 43 \\
\hline & & & 3.67 & $<0.001$ & 20 & 30 & 58 & 20 & 32 & 52 \\
\hline \multirow[t]{3}{*}{ R inferior parietal lobule (BA 40) } & 58 & 0.004 & 3.48 & $<0.001$ & 54 & -48 & 48 & 53 & -44 & 46 \\
\hline & & & 3.46 & $<0.001$ & 50 & -56 & 50 & 50 & -52 & 49 \\
\hline & & & 3.43 & $<0.001$ & 46 & -46 & 40 & 46 & -43 & 39 \\
\hline
\end{tabular}

R, Right; L, left; BA, Brodmann area.

hemisphere (supplemental Fig. 1, available at www.jneurosci.org as supplemental material).

\section{fMRI activity changes related to the observation of unpleasant stimuli}

Cortical foci activated when comparing the observation of painful and neutral video clips $(\mathrm{P}-\mathrm{N})$ were found in the perigenual anterior cingulate cortex (pACC) and in the left inferior postcentral gyrus (Fig. 4, top; Table 1). The reverse contrast $(\mathrm{N}-\mathrm{P})$ showed clusters in the prefrontal cortex, middle frontal gyrus, inferior parietal lobule (IPL), and medial parietal cortex/superior parietal lobule of the right hemisphere (Table 1).

Regions of higher activity during the observation of disgusting than during the observation of neutral video-clips $(D-N)$ were detected in the medial prefrontal cortex (MPF)/subgenual ACC (sACC), MCC, posterior cingulate cortex (PCC), and right PO (Fig. 4, bottom, Table 2). The reverse contrast $(\mathrm{N}-\mathrm{D})$ revealed clusters in the right superior frontal gyrus and IPL (Table 2).
In the conjunction analysis $[(\mathrm{P}-\mathrm{N})+(\mathrm{D}-\mathrm{N})]$, active foci were found in the sACC/MPF cortex, MCC and PCC, the left posterior insula, and the right PO (Fig. 5, Table 3).

Clusters that were more active during the observation of neutral stimuli than during the observation of both kinds of unpleasant stimuli $[(\mathrm{N}-\mathrm{P})+(\mathrm{N}-\mathrm{D})]$ were found in the right middle and superior frontal gyri and in the right IPL/supramarginal gyrus (Table 3) (supplemental Fig. 2, available at www.jneurosci. org as supplemental material).

\section{fMRI activity changes specifically related to the observation} of painful or disgusting stimuli

Clusters that were significantly more active during the observation of painful than disgusting stimuli $[(P-N)-(D-N)]$ were found in the left parietal cortex (Table 4, Fig. 6). One focus was centered in the PO and extended toward the adjacent IPL and inferior postcentral gyrus. Two more dorsal foci included portions of the postcentral gyrus and posterior parietal cortex. It is 
Mid-Cingulate Cortex $(0,2,36)$

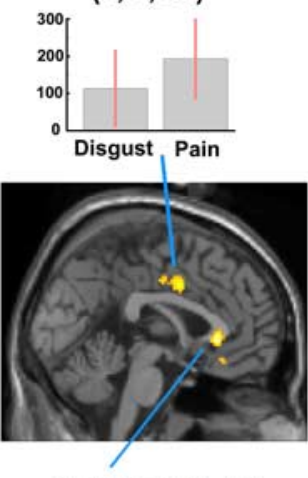

$\operatorname{sACC}(-2,26,-2)$

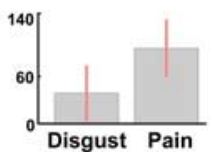

Posterior Cingulate Cortex $(-6,-62,14)$
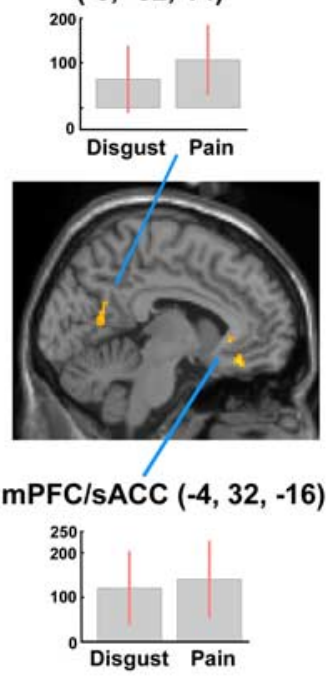

Medial Sup. Frontal Gyrus $(-16,40,32)$
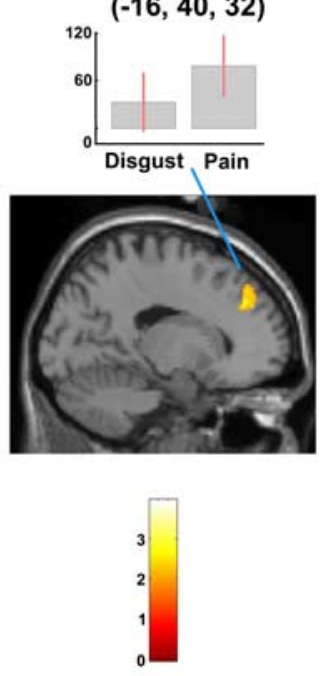
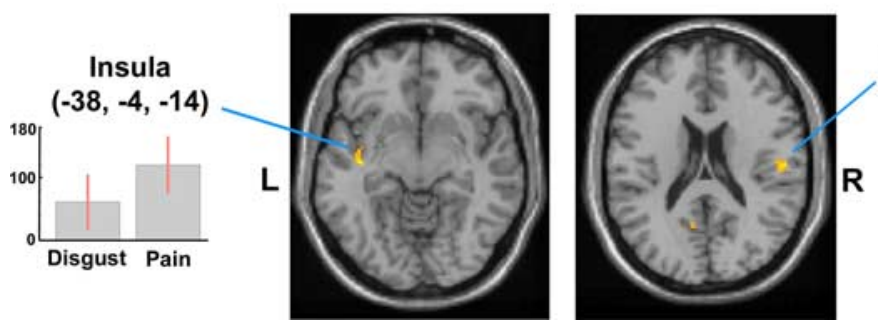

Figure 5. Clusters showing higher activity during the observation of both painful and disgusting versus neutral video clips $[(P-N)+(D-N)]$. Cingulate and prefrontal foci are displayed on sagittal sections (top), left insular and right parietal foci on axial sections (bottom) from the MNI template. Plots of parameter estimates (mean \pm SEM of 15 subjects) of the effects of $P$ $\mathrm{N}$ and $\mathrm{D}-\mathrm{N}$ observation for peak activity voxels are also shown. Random-effect analysis, height threshold of $p<0.001$ and cluster threshold of $p<0.05$ (both uncorrected). R, Right side of the brain; L, left side of the brain.

worth noting that no significant fMRI signal decrease was found in these regions when comparing disgusting to neutral stimuli (Table 2). Similar results were obtained by the direct comparison $(\mathrm{P}-\mathrm{D})$ (data not shown).

Clusters in PCC and medial parietal cortex were significantly more active during the observation of $\mathrm{D}$ than $\mathrm{P}$ stimuli $[(\mathrm{D}-$ $\mathrm{N})-(\mathrm{P}-\mathrm{N})$ ] (Table 4). However, whereas the PCC cluster appears to be specifically related to an increase in activity during the observation of D stimuli, the clusters in the medial parietal cortex reflects a significant decrease of fMRI signals during the observation of $\mathrm{P}$ versus $\mathrm{N}$ stimuli (Fig. 7, Table 1).

\section{Parametric analysis}

In the parametric analysis using the unpleasantness ratings only, no significant cluster was detected at the adopted statistical threshold. However, when the individual differences in susceptibility were taken into account (see Materials and Methods), active foci related to unpleasantness were found in the left anterior insula and superior parietal lobule, as well as in the sACC and in the right middle frontal gyrus (Table 5, Fig. 8).

\section{Discussion}

To our knowledge, this is the first fMRI study aimed at comparing the neural circuits involved in the visual detection of noxious versus other unpleasant/aversive stimuli delivered at specific body parts. Our results show partially overlapping brain networks, which may underlie affective and motor reactions to the
Parietal Operculum $(56,-16,20)$

observation of different kinds of aversive events (Decety and Jackson, 2004; Gallese et al., 2004). Specific increases in the activity of left parietal foci were related to noxious versus disgusting events.

\section{Brain regions involved in the} observation of unpleasant stimuli

The cingulate cortex and insula are key structures in processing information about emotionally relevant somatosensory stimuli and in the associated bodily and vegetative reactions (Craig, 2003; Critchley et al., 2004: Vogt, 2005; Tsuchiya and Adolphs, 2007); our findings extend the results obtained in different models of pain empathy (see Introduction), as well as in studies focusing on negative facial expressions unrelated to pain (for review, see Adolphs, 2002; Phan et al., 2002).

The enhanced activity in the anterior cingulate is interesting in light of its proposed role in pain affect (Vogt, 2005; Kulkarni et al., 2007). The subcallosal portion is anatomically and functionally connected with the medial orbitofrontal and ventral posterior cingulate cortices (Vogt et al., 2006; Margulies et al., 2007), which in turn can be involved in self-monitoring and judgment about one's own and other individuals' emotional states (Ochsner et al., 2004; Vogt, 2005).

pACC foci have rarely been described so far in association with the observation of noxious events (Morrison et al., 2004); indeed, an intriguing difference between our present data and previous studies (Jackson et al., 2006a) is the more consistent activation in pACC than in aMCC. The most likely explanation lies in differences in the cognitive sets in the various studies. First, our event-related experimental design likely minimized anticipation-related effects, which can enhance aMCC activity (Ploghaus et al., 1999; Porro et al., 2002; Nitschke et al., 2006). Second, our volunteers rated unpleasantness after each stimulus, and there is evidence that attention to the perceived unpleasantness selectively increases blood flow in pACC/sACC (but not in MCC) after painful laser stimuli (Kulkarni et al., 2005).

Both kinds of aversive stimuli can implicitly trigger stereotyped withdrawal reactions, which may involve pMCC (Niddam et al., 2005; Morrison et al., 2007). The putative nodes of the human mirror system [ventral premotor cortex and posteroinferior parietal cortex (Rizzolatti and Craighero, 2004)] were also active in all three conditions, probably in relation with the observation of body part movements; however, we found no activation in these areas specific for the aversive stimuli.

Our findings of the left anterior insula focus whose activity was related to the perceived unpleasantness, depending on each subject's susceptibility to the stimuli, is in line with electrophysiological (Krolak-Salmon et al., 2003), lesion (Calder et al., 2000), and brain mapping (Phillips et al., 1997; Schienle et al., 2002; Wicker et al., 2003; Wright et al., 2004) studies on the involvement of this region in feeling and recognizing disgust. The results of a meta-analysis on neuroimaging studies of emotion (Wager et al., 2003) also showed 


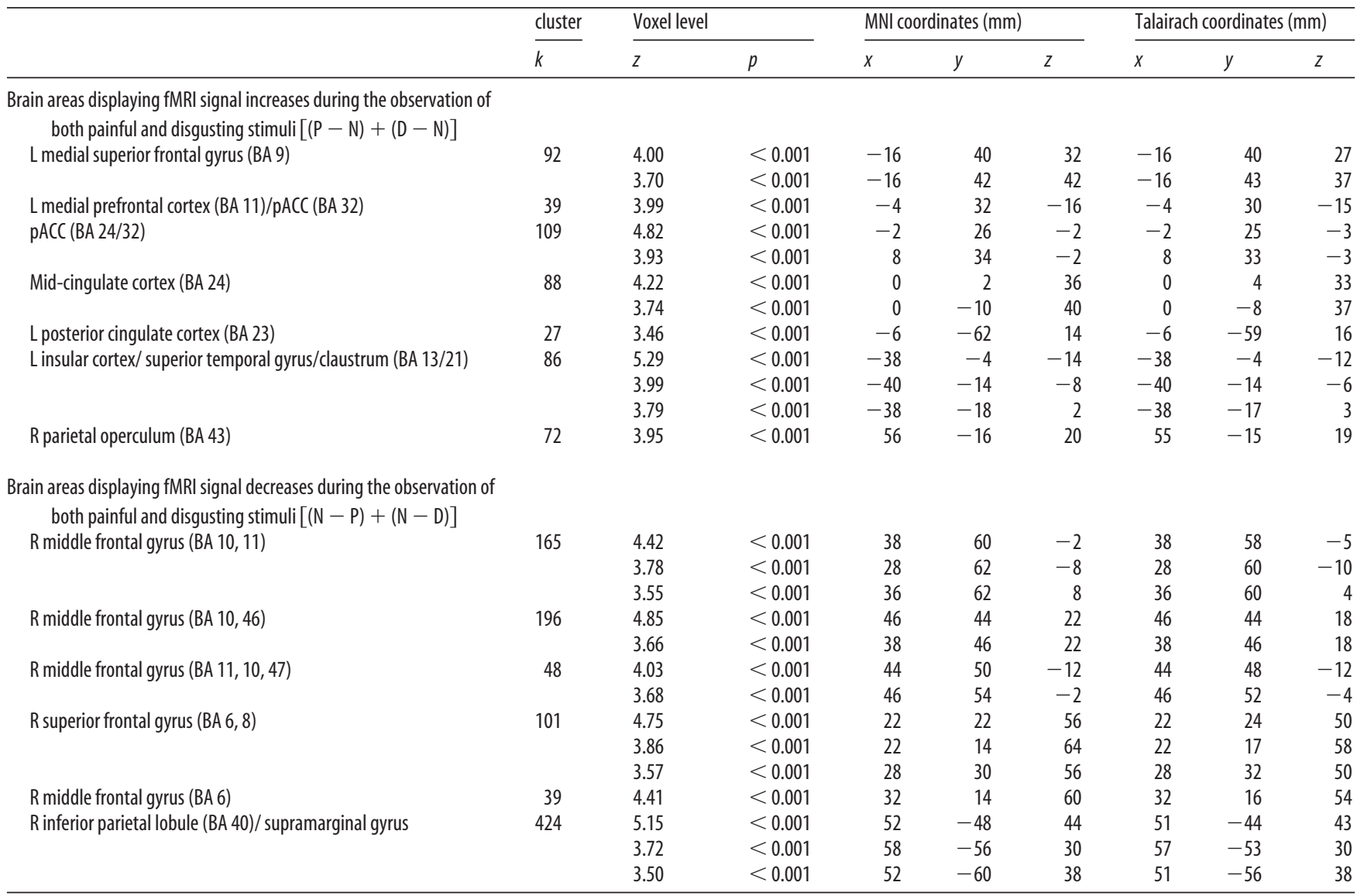

L, Left; $R$, right; $B A$, Brodmann area.

Table 4. fMRI signal increases specifically related to the observation of painful or disgusting stimuli

\begin{tabular}{|c|c|c|c|c|c|c|c|c|c|c|}
\hline & \multicolumn{2}{|c|}{ Cluster level } & \multicolumn{2}{|c|}{ Voxel level } & \multicolumn{3}{|c|}{ MNI coordinates (mm) } & \multicolumn{3}{|c|}{ Talairach coordinates (mm) } \\
\hline & $k$ & $p$ & $z$ & $p$ & $x$ & $y$ & $z$ & $x$ & $y$ & $z$ \\
\hline \multicolumn{11}{|l|}{ Painful $>$ disgusting $[(P-N)-(D-N)]$} \\
\hline \multirow[t]{3}{*}{ L postcentral gyrus/parietal operculum (BA 43) } & 157 & $<0.001$ & 3.98 & $<0.001$ & -62 & -18 & 32 & -61 & -16 & 30 \\
\hline & & & 3.77 & $<0.001$ & -52 & -24 & 12 & -51 & -23 & 12 \\
\hline & & & 3.44 & $<0.001$ & -60 & -20 & 16 & -59 & -19 & 16 \\
\hline \multirow[t]{3}{*}{ L postcentral gyrus/L posterior parietal cortex } & 192 & $<0.001$ & 4.25 & $<0.001$ & -38 & -42 & 60 & -38 & -38 & 57 \\
\hline & & & 4.02 & $<0.001$ & -34 & -38 & 50 & -34 & -35 & 48 \\
\hline & & & 3.52 & $<0.001$ & -32 & -50 & 66 & -32 & -45 & 63 \\
\hline L Postcentral gyrus/inferior parietal lobule (BA 40) & 112 & 0.001 & 3.96 & $<0.001$ & -56 & -26 & 40 & -55 & -23 & 38 \\
\hline \multicolumn{11}{|l|}{ Disgusting $>$ painful $[(D-N)-(P-N)]$} \\
\hline R posterior cingulate (BA 31) & 38 & $<0.05$ & 3.61 & $<0.001$ & 18 & -58 & 22 & 18 & -55 & 23 \\
\hline $\mathrm{R}$ medial parietal cortex (BA 7) & 159 & $<0.001$ & 4.09 & $<0.001$ & 16 & -76 & 40 & 16 & -72 & 40 \\
\hline $\mathrm{R}$ medial parietal cortex (BA 7) & 34 & 0.05 & 3.50 & $<0.001$ & 14 & -62 & 54 & 14 & -58 & 53 \\
\hline
\end{tabular}

L, Left; $R$, right; $B A$, Brodmann area.

an above-chance density of withdrawal-related activation foci in the left (but not in the right) mid-insula. In contrast, the focus in the left posterior insula appears to be predominantly involved in representing noxious stimuli (Peyron et al., 2002).

The overlapping activation in the right PO during the observation of noxious and disgusting events is interesting in light of the evidence for the involvement of right somatosensory-related cortices during the observation of facial expressions of pain (Botvinick et al., 2005) and in the recognition of basic emotions from facial expressions (Adolphs et al., 2000). These latter results were interpreted as if emotion recognition may involve construction of on-line somatosensory representation by internal simulation (Adolphs, 2002; Gallese et al., 2004).

\section{Activation of the parietal cortex: a way for recognizing} noxious environmental events?

Our findings of left parietal foci related to the observation of painful stimuli add to recent evidence of the involvement of cortical areas in or around PO during the observation of somatosensory stimuli, either innocuous (Keysers et al., 2004; Blakemore et al., 2005) or noxious (Jackson et al., 2006b; Lloyd et al., 2006; Morrison and Downing, 2007; Moriguchi et al., 2007), as well as in other paradigms of pain empathy (Singer et al., 2006).

The PO and adjacent portion of IPL are likely to play a significant role in attention to noxious stimuli (Duncan and Albanese, 2003). Indeed, neurons in PO and IPL have visual responses and display more intense neuronal activation after actual noxious 


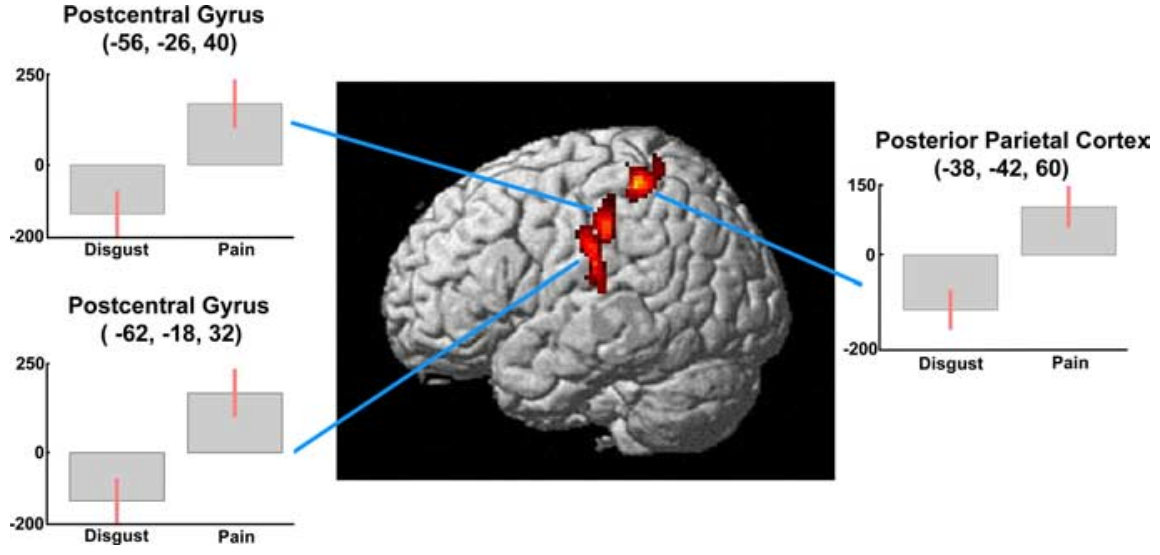

Figure 6. Three-dimensional rendering showing cortical clusters in the left parietal cortex, more active during the observation of painful than disgusting video clips $[(P-N)-(D-N)]$. Plots of parameter estimates for peak activity voxels refer to the $P-$ $\mathrm{N}$ and $\mathrm{D}-\mathrm{N}$ contrasts, respectively.

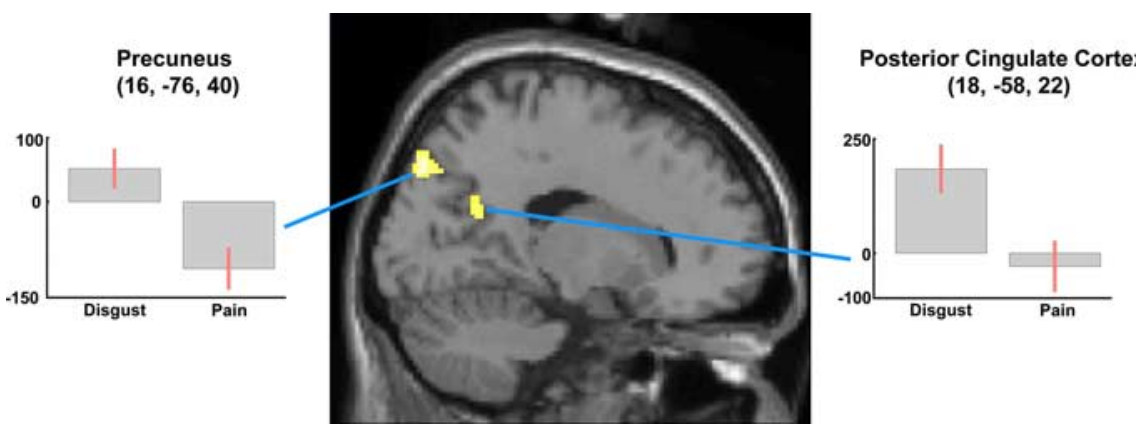

Figure 7. Sagittal section showing cortical clusters more active during the observation of disgusting than painful video clips $[(D-N)-(P-N)]$. Plots of parameter estimates for peak activity voxels refer to the $P-N$ and $D-N$ contrasts, respectively.

than non-noxious somatosensory stimuli (Dong et al., 1994). Parietal areas are involved in sensory-discriminative aspects of pain (Porro, 2003; Price et al., 2003) and specifically in the spatial localization of painful stimuli (Kanda et al., 1999; Oshiro et al., 2007; Porro et al., 2007) and are heavily connected with insular and cingulate cortices (Craig, 2003; Vogt, 2005).

The location of active foci during the observation of painful events is similar to that found during actual noxious mechanical stimulation of the right hand (Lui et al., 2008b). In contrast, noxious-related foci we found in the left inferior parietal cortex are far more rostral than the ones active during the observation of fearful bodily expressions (de Gelder et al., 2004) or of facial expressions of pain (Saarela et al., 2007) .

In the present study, we did not explicitly instruct volunteers to imagine themselves experiencing pain (Jackson et al., 2006b; Ogino et al., 2007) while looking at noxious or unpleasant stimuli. Yet, observing a scene with somatic stimuli (e.g., a needle penetrating the skin of another individual) can elicit a sensation as if the stimulus acted on one's own skin: this experience is usually specifically related to the observed body part (Freedberg and Gallese, 2007). Our finding that viewing images of wounds delivered to specific body parts yields to greater activation of parietal areas than viewing other emotional or neutral stimuli might be related to a difference in the degree of implicit "embodied simulation" (Damasio, 1994; Adolphs, 2002; Gallese et al., 2004) in the three conditions. This in turn might be attributable to the penetrating nature of the observed noxious stimuli (Avenanti et al., 2006).

The embodied simulation theory would be more convincingly demonstrated by a somatotopic arrangement of observation-related foci in SI, which, in agreement with other fMRI studies (Jackson et al., 2005, 2006b; Cheng et al., 2007), we could not demonstrate here. Conflicting results about visually evoked activity in SI have been obtained in fMRI (Keysers et al., 2004; Blakemore et al., 2005) and magnetoencephalographic (Schaefer et al., 2005) studies. Bufalari et al. (2007) demonstrated that viewing painful stimuli delivered to the hand of a human model increased the amplitude of the P45 component (thought to originate from the crown of the postcentral gyrus) of the brain potentials evoked by median nerve stimulation. Failure to show an observationinduced somatotopic activation by conventional fMRI techniques could be related to their inadequate sensitivity to detect weak and/or transient activations; high temporal and spatial resolution fMRI studies could be useful to address this issue.

Another explanation for pain-specific parietal foci may be related to the automatic initiation of movements to escape the potential source of pain. However, this explanation seems unlikely. First, avoidance behavior is likely to be triggered by disgusting stimuli, too. Second, the pattern of parietal activation does not seem to be specific to upper arm movement planning or imagery (Ruby and Decety, 2003; Lui et al., 2008a). Third, they are not accompanied by a specific premotor/posterior parietal cortex activation.

Because we did not test the responses to stimuli presented to the left hand or foot, it remains to be investigated whether the differential left parietal activity is indeed related to the body side being observed. Nevertheless, our data suggest that parietal areas are involved in discriminating between noxious and other environmental unpleasant stimuli.

Our hypothesis is apparently in contrast with that proposed by Singer et al. (2004), claiming that pain empathy is based on the activation of brain structures engaged in affective but not in the sensory experience of pain. As mentioned in Introduction, however, our volunteers faced a very different task from that investigated by Singer et al. (2004, 2006); for instance, direct visual information on damaging stimuli was absent in the Singer et al. paradigm. There is recent evidence that top-down representations (e.g., related to intensity coding) of painful experiences do not necessarily involve the activation of parietal areas (Kong et al., 2006), unless specific sensory features (e.g., spatial location) are recalled (Albanese et al., 2007). However, the parietal cortex is consistently activated during actual acute pain perception (Porro, 2003), as well as during pain anticipation (Sawamoto et al., 2000; Porro et al., 2002; Berns et al., 2006). Our data support the hypothesis that recruiting brain regions involved in pain processing, including sensory-discriminative-related regions, underlie the recognition of noxious cutaneous stimuli on the basis of online visual information. 
Table 5. Cortical areas showing a linear signal increase with the perceived unpleasantness and the IP-R general score

\begin{tabular}{|c|c|c|c|c|c|c|c|c|c|}
\hline & \multirow{2}{*}{$\frac{\text { Cluster }}{k}$} & \multicolumn{2}{|c|}{ Voxel level } & \multicolumn{3}{|c|}{ MNI coordinates (mm) } & \multicolumn{3}{|c|}{ Talairach coordinates (mm) } \\
\hline & & $Z$ & $p$ & $x$ & $y$ & $Z$ & $x$ & $y$ & $z$ \\
\hline L anterior insula & 20 & 4.31 & $<0.001$ & -28 & 16 & -14 & -28 & 15 & -13 \\
\hline R middle frontal gyrus (BA 10) & 14 & 4.04 & $<0.001$ & 42 & 52 & 14 & 42 & 51 & 10 \\
\hline L middle occipital gyrus (BA 19) & 16 & 3.95 & $<0.001$ & -28 & -78 & 14 & -28 & -75 & 17 \\
\hline \multirow[t]{2}{*}{ R middle frontal gyrus (BA 10,47) } & 37 & 3.94 & $<0.001$ & 46 & 54 & 2 & 46 & 52 & -1 \\
\hline & & 3.82 & $<0.001$ & 48 & 50 & -6 & 48 & 48 & -7 \\
\hline $\operatorname{pACC}(\mathrm{BA} 24,32)$ & 19 & 3.84 & $<0.001$ & -2 & 24 & -4 & -2 & 23 & -5 \\
\hline R middle frontal gyrus (BA 9) & 15 & 3.77 & $<0.001$ & 44 & 22 & 30 & 44 & 23 & 26 \\
\hline L superior parietal lobule (BA 7) & 19 & 3.70 & $<0.001$ & -22 & -60 & 38 & -22 & -56 & 38 \\
\hline R angular gyrus (BA 39) & 26 & 3.57 & $<0.001$ & 36 & -72 & 30 & 36 & -68 & 31 \\
\hline
\end{tabular}

L, Left; $R$, right; $B A$, Brodmann area.

\section{References}

Adolphs R (2002) Neural systems for recognizing emotion. Curr Opin Neurobiol 12:169-177.

Adolphs R, Damasio H, Tranel D, Cooper G, Damasio AR (2000) A role for somatosensory cortices in the visual recognition of emotion as revealed by three-dimensional lesion mapping. J Neurosci 20:2683-2690.

Albanese MC, Duerden EG, Rainville P, Duncan GH (2007) Memory traces of pain in human cortex. J Neurosci 27:4612-4620.

Avenanti A, Bueti D, Galati G, Aglioti SM (2005) Transcranial magnetic stimulation highlights the sensorimotor side of empathy for pain. Nat

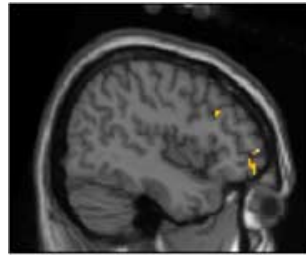

Middle Frontal Gyrus $(46,54,2)$

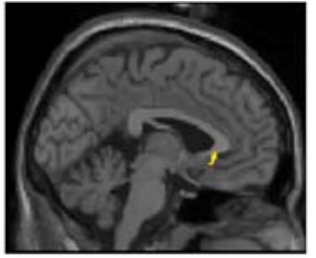

pACC

$(2,24,-4)$

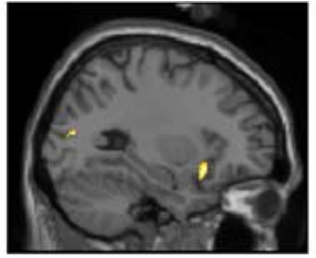

Anterior Insula

$(-28,16,-14)$

Figure 8. Sagittal sections showing cortical clusters whose activity was linearly correlated with the perceived unpleasantness and susceptibility to fearful stimuli (for details, see Materials and Methods). Neurosci 8:955-960.

Avenanti A, Paluello IM, Bufalari I, Aglioti SM (2006) Stimulus-driven modulation of motor-evoked potentials during observation of others' pain. NeuroImage 32:316-324.

Berns GS, Chappelow J, Cekic M, Zink CF, Pagnoni G, Martin-Skurski ME (2006) Neurobiological substrates of dread. Science 312:754-758.

Blakemore SJ, Bristow D, Bird G, Frith C, Ward J (2005) Somatosensory activations during the observation of touch and a case of vision-touch synaesthesia. Brain 128:1571-1583.

Botvinick M, Jha AP, Bylsma LM, Fabian SA, Solomon PE, Prkachin KM (2005) Viewing facial expressions of pain engages cortical areas involved in the direct experience of pain. NeuroImage 25:312-319.

Bufalari I, Aprile T, Avenanti A, Di Russo F, Aglioti SM (2007) Empathy for pain and touch in the human somatosensory cortex. Cereb Cortex 17:2553-2561.

Calder AJ, Keane J, Manes F, Antoun N, Young AW (2000) Impaired recognition and experience of disgust following brain injury. Nat Neurosci 3:1077-1078.

Cheng Y, Lin C-P, Liu H-L, Hsu Y-Y, Lim K-E, Hung D, Decety J (2007) Expertise modulates the perception of pain in others. Curr Biol 17:1708-1713.

Craig AD (2003) Interoception: the sense of the physiological condition of the body. Curr Opin Neurobiol 13:500-505.

Critchley HD, Wiens S, Rotshtein P, Ohman A, Dolan RJ (2004) Neural systems supporting interoceptive awareness. Nat Neurosci 7:189-195.

Damasio AR (1994) Descartes' error: emotion, reason, and the human brain. New York: Oxford UP.

de Gelder B, Snyder J, Greve D, Gerard G, Hadjikhani N (2004) Fear fosters flight: a mechanism for fear contagion when perceiving emotion expressed by a whole body. Proc Natl Acad Sci USA 101:16701-16706.

de Vignemont F, Singer T (2006) The empathic brain: how, when and why? Trends Cogn Sci 10:435-441.

Decety J, Jackson PL (2004) The functional architecture of human empathy. Behav Cogn Neurosci Rev 3:71-100.

Dong WK, Chudler EH, Sugiyama K, Roberts VJ, Hayashi T (1994) Somatosensory, multisensory, and task-related neurons in cortical area $7 \mathrm{~b}(\mathrm{PF})$ of unanesthetized monkeys. J Neurophysiol 72:542-564.

Duncan GH, Albanese MC (2003) Is there a role for the parietal lobes in the perception of pain? Adv Neurol 93:69-86.

Freedberg D, Gallese V (2007) Motion, emotion and empathy in esthetic experience. Trends Cogn Sci 11:197-203.

Gallese V, Keysers C, Rizzolatti G (2004) A unifying view of the basis of social cognition. Trends Cogn Sci 8:396-403.

Godinho F, Magnin M, Frot M, Perchet C, Garcia-Larrea L (2006) Emotional modulation of pain: is it the sensation or what we recall? J Neurosci 26:11454-11461.

Goubert L, Craig KD, Vervoort T, Morley S, Sullivan MJ, de C Williams, Cano A, Crombez G (2005) Facing others in pain: the effects of empathy. Pain 118:285-288.

Gu X, Han S (2007) Attention and reality constraints on the neural processes of empathy for pain. NeuroImage 36:256-267.

Jackson PL, Meltzoff AN, Decety J (2005) How do we perceive the pain of others? A window into the neural processes involved in empathy. NeuroImage 24:771-779.

Jackson PL, Rainville P, Decety J (2006a) To what extent do we share the pain of others? Insight from the neural bases of pain empathy. Pain 125:5-9.

Jackson PL, Brunet E, Meltzoff AN, Decety J (2006b) Empathy examined through the neural mechanisms involved in imagining how I feel versus how you feel pain. Neuropsychologia 44:752-761.

Kanda M, Shindo K, Xu X, Fujiwara N, Ikeda A, Nagamine T, Shibasaki H (1999) Cortical mechanisms underlying point localization of pain spot as studied by event-related potentials following CO2 laser stimulation in man. Exp Brain Res 127:131-140.

Keysers C, Wicker B, Gazzola V, Anton JL, Fogassi L, Gallese V (2004) A touching sight: SII/PV activation during the observation and experience of touch. Neuron 42:335-346.

Kong J, White NS, Kwong KK, Vangel MG, Rosman IS, Gracely RH, Gollub RL (2006) Using fMRI to dissociate sensory encoding from cognitive evaluation of heat pain intensity. Hum Brain Mapp 27:715-721.

Krolak-Salmon P, Henaff MA, Isnard J, Tallon-Baudry C, Guenot M, Vighetto A, Bertrand O, Mauguiere F (2003) An attention modulated response to disgust in human ventral anterior insula. Ann Neurol 53:446-453.

Kulkarni B, Bentley DE, Elliott R, Youell P, Watson A, Derbyshire SW, Frackowiak RS, Friston KJ, Jones AK (2005) Attention to pain localization and unpleasantness discriminates the functions of the medial and lateral pain systems. Eur J Neurosci 21:3133-3142.

Kulkarni B, Bentley DE, Elliott R, Julyan PJ, Boger E, Watson A, Boyle Y, El-Deredy W, Jones AK (2007) Arthritic pain is processed in brain areas concerned with emotions and fear. Arthritis Rheum 56:1345-1354.

Lamm C, Batson CD, Decety J (2007) The neural substrate of human em- 
pathy: effects of perspective-taking and cognitive appraisal. J Cogn Neurosci 19:42-58.

Lloyd D, Morrison I, Roberts N (2006) Role for human posterior parietal cortex in visual processing of aversive objects in peripersonal space. J Neurophysiol 95:205-214.

Lui F, Buccino G, Duzzi D, Benuzzi F, Crisi G, Baraldi P, Nichelli P, Porro CA, Rizzolatti G (2008a) Neural substrates for observing and imagining non object-directed actions. Social Neurosci, in press.

Lui F, Duzzi D, Corradini M, Serafini M, Baraldi P, Porro CA (2008b) Touch or pain? Spatiotemporal patterns of cortical fMRI activity following brief mechanical stimuli. Pain, in press.

Margulies DS, Kelly AM, Uddin LQ, Biswal BB, Castellanos FX, Milham MP (2007) Mapping the functional connectivity of anterior cingulate cortex. NeuroImage 37:579-588.

Moriguchi Y, Decety J, Ohnishi T, Maeda M, Mori T, Nemoto K, Matsuda H, Komaki G (2007) Empathy and judging other's pain: an fMRI study of alexithymia. Cereb Cortex 17:2223-2234.

Morrison I, Downing PE (2007) Organization of felt and seen pain responses in anterior cingulate cortex. NeuroImage 37:642-651.

Morrison I, Lloyd D, di Pellegrino G, Roberts N (2004) Vicarious responses to pain in anterior cingulate cortex: is empathy a multisensory issue? Cogn Affect Behav Neurosci 4:270-278.

Morrison I, Peelen MV, Downing PE (2007) The sight of others' pain modulates motor processing in human cingulate cortex. Cereb Cortex 17:2214-2222.

Niddam DM, Chen LF, Wu YT, Hsieh JC (2005) Spatiotemporal brain dynamics in response to muscle stimulation. NeuroImage 25:942-951.

Nitschke JB, Sarinopoulos I, Mackiewicz KL, Schaefer HS, Davidson RJ (2006) Functional neuroanatomy of aversion and its anticipation. NeuroImage 29:106-116.

Ochsner KN, Knierim K, Ludlow DH, Hanelin J, Ramachandran T, Glover G, Mackey SC (2004) Reflecting upon feelings: an fMRI study of neural systems supporting the attribution of emotion to self and other. J Cogn Neurosci 16:1746-1772.

Ogino Y, Nemoto H, Inui K, Saito S, Kakigi R, Goto F (2007) Inner experience of pain: imagination of pain while viewing images showing painful events forms subjective pain representation in human brain. Cereb Cortex 17:1139-1146.

Oldfield RC (1971) The assessment and analysis of handedness: the Edinburgh Inventory. Neuropsychologia 9:97-113.

Oshiro Y, Quevedo AS, McHaffie JG, Kraft RA, Coghill RC (2007) Brain mechanisms supporting spatial discrimination of pain. J Neurosci 27:3388-3394.

Peyron R, Frot M, Schneider F, Garcia-Larrea L, Mertens P, Barral FG, Sindou M, Laurent B, Mauguiere F (2002) Role of operculoinsular cortices in human pain processing: converging evidence from PET, fMRI, dipole modeling, and intracerebral recordings of evoked potentials. NeuroImage 17:1336-1346.

Phan KL, Wager T, Taylor SF, Liberzon I (2002) Functional neuroanatomy of emotion: a meta-analysis of emotion activation studies in PET and fMRI. NeuroImage 16:331-348.

Phillips ML, Young AW, Senior C, Brammer M, Andrew C, Calder AJ, Bullmore ET, Perrett DI, Rowland D, Williams SC, Gray JA, David AS (1997) A specific neural substrate for perceiving facial expressions of disgust. Nature 389:495-498.

Ploghaus A, Tracey I, Gati JS, Clare S, Menon RS, Matthews PM, Rawlins JN (1999) Dissociating pain from its anticipation in the human brain. Science 284:1979-1981.

Porro CA (2003) Functional imaging and pain: behavior, perception, and modulation. The Neuroscientist 9:354-369.

Porro CA, Baraldi P, Pagnoni G, Serafini M, Facchin P, Maieron M, Nichelli
P (2002) Does anticipation of pain affect cortical nociceptive circuits? J Neurosci 22:3206-3214.

Porro CA, Martinig M, Facchin P, Maieron M, Jones AK, Fadiga L (2007) Parietal cortex involvement in the localization of tactile and noxious mechanical stimuli: a transcranial magnetic stimulation study. Behav Brain Res 178:183-189.

Price DD, Greenspan JD, Dubner R (2003) Neurons involved in the exteroceptive function of pain. Pain 106:215-219.

Rainville P (2002) Brain mechanisms of pain affect and pain modulation. Curr Opin Neurobiol 12:195-204.

Rizzolatti G, Craighero L (2004) The mirror neuron system. Annu Rev Neurosci 27:169-192.

Ruby P, Decety J (2003) What you believe versus what you think they believe: a neuroimaging study of conceptual perspective-taking. Eur J Neurosci 17:2475-2480.

Saarela MV, Hlushchuk Y, Williams AC, Schurmann M, Kalso E, Hari R (2007) The compassionate brain: humans detect intensity of pain from another's face. Cereb Cortex 17:230-237.

Sanavio E, Bertolotti G, Michielin P, Vidotto G, Zotti AM (1986) CBA-2.0 Scale Primarie. Florence, Italy: Organizzazioni Speciali.

Sawamoto N, Honda M, Okada T, Hanakawa T, Kanda M, Fukuyama H, Konishi J, Shibasaki H (2000) Expectation of pain enhances responses to nonpainful somatosensory stimulation in the anterior cingulate cortex and parietal operculum/posterior insula: an event-related functional magnetic resonance imaging study. J Neurosci 20:7438-7445.

Schaefer M, Heinze H-J, Rotte M (2005) Seeing the hand being touched modulates the primary somatosensory cortex. NeuroReport 16:1101-1105.

Schienle A, Stark R, Walter B, Blecker C, Ott U, Kirsch P, Sammer G, Vaitl D (2002) The insula is not specifically involved in disgust processing: an fMRI study. NeuroReport 13:2023-2026.

Simon D, Craig KD, Miltner WH, Rainville P (2006) Brain responses to dynamic facial expressions of pain. Pain 126:309-318.

Simon D, Craig KD, Gosselin F, Belin P, Rainville P (2008) Recognition and discrimination of prototypical dynamic expressions of pain and emotions. Pain, in press.

Singer T, Seymour B, O'Doherty J, Kaube H, Dolan RJ, Frith CD (2004) Empathy for pain involves the affective but not sensory components of pain. Science 303:1157-1162.

Singer T, Seymour B, O’Doherty JP, Stephan KE, Dolan RJ, Frith CD (2006) Empathic neural responses are modulated by the perceived fairness of others. Nature 439:466-469.

Talairach J, Tournoux P (1988) Co-planar stereotaxic atlas of the human brain. New York: Thieme Medical Publisher.

Tsuchiya N, Adolphs R (2007) Emotion and consciousness. Trends Cogn Sci 11:158-167.

Vogt BA (2005) Pain and emotion interactions in subregions of the cingulate gyrus. Nat Rev Neurosci 6:533-544.

Vogt BA, Vogt L, Laureys S (2006) Cytology and functionally correlated circuits of human posterior cingulate areas. NeuroImage 29:452-466.

Wager TD, Phan KL, Liberzon I, Taylor SF (2003) Valence, gender, and lateralization of functional brain anatomy in emotion: a meta-analysis of findings from neuroimaging. NeuroImage 19:513-531.

Wicker B, Keysers C, Plailly J, Royet JP, Gallese V, Rizzolatti G (2003) Both of us disgusted in My insula: the common neural basis of seeing and feeling disgust. Neuron 40:655-664.

Williams AC (2002) Facial expression of pain: an evolutionary account. Behav Brain Sci 25:439-488.

Wright P, He G, Shapira NA, Goodman WK, Liu Y (2004) Disgust and the insula: fMRI responses to pictures of mutilation and contamination. NeuroReport 15:2347-2351. 